\title{
PATRIMONIO CERÁMICO GUARANí
}

\author{
Ceramic heritage guarani
}

\section{Silvia Jordán*, Andrea Dormond**, Carlos Boián*** y Mirna Rivas****}

\section{Resumen}

La presente propuesta se basa en el estudio integral de piezas de cerámica arqueológica guaraní, en relación con su morfología, tecnología, estilo y usos. Esto nos ha permitido realizar reproducciones de las diferentes tipologías a escala, piezas que en idioma guaraní se denominan: japepó, cambuchí, ñaetá, ñaembé, cambuchí caguavá y Ñamópiu. El taller surgió como necesidad de recrear conocimientos - prácticas en relación al hacer del arte cerámico y la cultura mbyá guaraní, que se localiza en la provincia de Misiones. Nos valimos para ello de la reproducción de tiestos a partir de relevamientos realizados en museos y de la imitación de fragmentos cerámicos arqueológicos encontrados en la región, sobre todo en las márgenes de ríos y arroyos, identificados empíricamente a partir de una serie de rasgos característicos que determinan su origen guaraní.

Realizamos registros fotográficos de piezas existentes en diferentes colecciones, a fin de contar con ejemplos que permitan apreciar detalles, determinar rupturas y continuidades en el tratamiento de la fase externa de las cerámicas, -pintura roja sobre blanca, pintura blanca sobre roja; texturas como el acordelado, serrungulado, escobado, unguiculado y corrugado- y establecer los modos de modelado y quema de las mismas en hornos a cielo abierto

$$
<\text { Patrimonio }><\text { Cerámica }><\text { Tipología }><\text { Guaraní }>
$$

\begin{abstract}
This proposal is based on comprehensive study of Guarani archaeological ceramics pieces, in relation to their morphology, technology, style and uses. This has allowed us to make scale reproductions of the different types of pieces. In the Guarani language, these pieces are called: japepó, cambuchí, ñaetá, ñaembé, cambuchí caguavá and Ñamópiu. The workshop emerged as a need to recreate knowledgepractices in relation to the Mbyá Guarani ceramic art and culture, located in the province of Misiones. In order to do so, it was necessary to pursue the reproduction of sherds from surveys conducted in museums and the imitation of archaeological ceramic fragments found in the region, especially on the banks of rivers and streams. These fragments were empirically identified from a number of characteristic features that determine their Guarani origin.

Besides were made photographic records of existing parts in different collections were made to have examples to see details, determine ruptures and continuities in the treatment of the outer phase of ceramics, red-paint on white, white on red paint, textures like acordelado, serrungulado, escobado, unguiculate, and corrugado-, and establish modes of modeling and burning them in open furnaces.
\end{abstract}

$$
<\text { Heritage }><\text { Ceramics }><\text { Typology }><\text { Guaraní }>
$$

\footnotetext{
* Doctora en Artes. UNaM.

** Profesora Titular. UNaM.

*** Técnico en Medios Audiovisuales y Fotografía. UNaM.

***** Profesora en Artes Plásticas y Técnico Ceramista.UNaM.
} 
La necesidad de socializar conocimientos en relación al arte cerámico y la cultura mbyá guaraní, se plantea como estrategia para favorecer el reconocimiento de estos bienes patrimoniales desde una mirada regional, como referentes simbólicos de identidades y memorias.

La propuesta es de carácter multidisciplinario, donde la historia, la arqueología, la antropología social, la formación específica en cerámica; conjugan diseño, fotografía y video. La principal motivación es la puesta en valor del patrimonio arqueológico guaraní, a través de su cerámica prehispánica, mediante el registro de imágenes que permitan su estudio y faciliten el trabajo de investigación. Los objetivos son:

- Sensibilizar como universidad pública, sobre la importancia de educar en un escenario de inclusión y diversidad cultural.

- Promover la preservación del patrimonio cultural de pueblos originarios, favoreciendo el rescate de objetos, ya sea de manera material o a través del registro fotográfico $\mathrm{y} / \mathrm{o}$ fílmico.

- Incentivar al conocimiento de la cerámica arqueológica guaraní, sobre todo entre los miembros de sus aldeas.

- Generar un espacio de interacción a fin de vincular a la comunidad con equipos de expertos que asesoren en el registro, rescate y conservación de la cerámica.

El abordaje es cualitativo, a fin de captar aspectos característicos de la cerámica guaraní, considerando la gran variedad de morfología, iconografía, tratamiento de superficie, aplicación de engobes, de óxidos minerales de la región y la utilización de tintes vegetales en frío. Entre las acciones que sirvieron a la recolección de datos, se encuentran la visita a museos y comunidades mbyá guaraní. Las entrevistas a expertos y a referentes, acompañadas de registros fotográficos y fílmicos. Realización de reproducciones a diferentes escalas, recreando las técnicas tradicionales de cerámica guaraní, de modelado y quemas a cielo abierto, de manera experimental. En síntesis, nos apoyamos en indagación y muestreo bibliográfico, registro etnográfico dentro del paradigma interpretativo-emancipatorio.

El trabajo plantea un estudio que integra morfología, tecnología y usos de la alfarería guaraní. Se busca ampliar el conocimiento de las producciones cerámicas realizadas por poblaciones de origen amazónico, a partir del relevamiento de tiestos arqueológicos que constituyen el patrimonio de diferentes museos y colecciones de la región denominada "de las Misiones". Esta abarca el Nordeste Argentino, principalmente las provincias de Misiones, Corrientes y Entre Ríos; el sur de Brasil y el sur de Paraguay.

En relación a esta temática, los textos existentes abordan cerámica precolombina de América en general y del Noroeste argentino en particular, siendo escasa la bibliografía referida a la producción cerámica de los guaraníes. Por otra parte, la comunidad mbyá guaraní, sabe por tradiciones orales de la existencia de estas tecnologías, pero no han tenido oportunidad de visualizarlas, al no ingresar a los espacios donde el "blanco" deposita los bienes que produjeron sus antepasados. Proponemos aportar material de estudio específico en nuestro idioma, respetando la fonética de la lengua guaraní, 
utilizando las imágenes, a fin de hacer más accesible su apreciación para profundizar el análisis y de este modo acompañar a los descendientes mbyá, a la apropiación e identificación con las vasijas cerámicas, en el reconocimiento y la recuperación de este patrimonio, hoy presente en la memoria de unos pocos ancianos.

Cabe señalar en este momento, que antes de la llegada de los europeos, los pueblos de la familia lingüística tupí-guaraní se expandieron desde la floresta amazónica en el norte de Brasil hasta el Río de la Plata. En Argentina, la selva de Misiones es una de las áreas de mayor concentración de asentamientos guaraníes, desde tiempos prehispánicos. El impacto que genera la llegada de los colonizadores como posteriormente la de los jesuitas a la zona, produjo hibridaciones culturales que modificaron el sistema de vida ancestral y los modos de producción de los mbyá. La presencia cerámica, se ha identificado a partir de una serie de rasgos característicos pero fundamentalmente, por la repetición de patrones en alfarería. Sin embargo, aunque han sido considerados rasgos diagnósticos guaraní, recién en los últimos años han cobrado mayor auge las investigaciones específicas sobre manufactura, iconografía y usos de la cerámica guaraní en la provincia de Misiones.

\section{Los caminos}

El proceso de indagación y relevamiento desarrollado, demandó sucesivas visitas del grupo, a instituciones que contaran con patrimonio cerámico arqueológico guaraní. En interacción con quienes abordan temas similares, se coincide en la necesidad de fortalecer un trabajo colaborativo interdisciplinario, a fin de generar nuevos aportes como material de estudio y de divulgación. Esto además sentaría las bases para conformar una bibliografía accesible en publicaciones de la universidad. El registro de imágenes del patrimonio cerámico realizado en los diferentes museos y la confrontación con autores que se refieren al tema, ha permitido identificar la morfología de las piezas de acuerdo a funciones y reconocerlas según la clasificación de Ruiz de Montoya ${ }^{1}$, José Brochado y más recientemente de Mariano Bonomo ${ }^{2}$, lo que ha facilitado la observación de detalles, rupturas y continuidades. Lo antedicho, se hace evidente en la cerámica, donde la inclusión del torno y los vidriados, se imponen como una necesidad de abastecer a las reducciones de elementos que sirvieran a la liturgia católica como candelabros, cálices, vasijas y utilitarios como platos, jarras, utensilios de uso doméstico con diseño típicamente español.

La principal diferencia entre los guaraní que sufrieron esta aculturación con la instauración del sistema reduccional y los originarios de otras zonas como el Gran Chaco y Paraguay, es que han dejado de producir la cerámica que los identificaba y se abocaron a continuar la tradición artesanal, con otras técnicas y materiales como la talla en madera o la cestería con fibras de güembé y de tacuapí. Y en este camino, las únicas producciones que se registran en algunas comunidades son las pipas o petynguá,

\footnotetext{
1 Ruiz de Montoya Antonio, Vocabulario y Tesoro de la Lengua Guaraní, cit. por La Salvia y Brochado (1989: 125 146).

2 Bonomo, Mariano, Dr. en Arqueología - Investigador de CONICET - UNLP/Facultad de Ciencias Naturales y Museo.
} 
modeladas con el barro ñaú local y cochuradas en fogones. El denominado "asiento de fogones" (Figura 1), es un lugar donde se reúnen los miembros de la comunidad en torno al fuego para compartir actividades comunitarias como el pirograbado de las tallas en madera y la cocción cerámica. Allí además, se toman las decisiones más importantes entre el cacique opyguá y el Consejo de ancianos. También es el lugar para compartir los alimentos, el mate, el tabaco y transmitir de una a otra generación sus cantos, danzas, "cantos sagrados", al decir del Padre Bartomeu Melià (2008; 9)3. Esta modalidad de reunión circular, es una institución social propia de los guaraní, que se mantiene viva y a resguardo a pesar de las interferencias propias de su inserción al mundo actual.

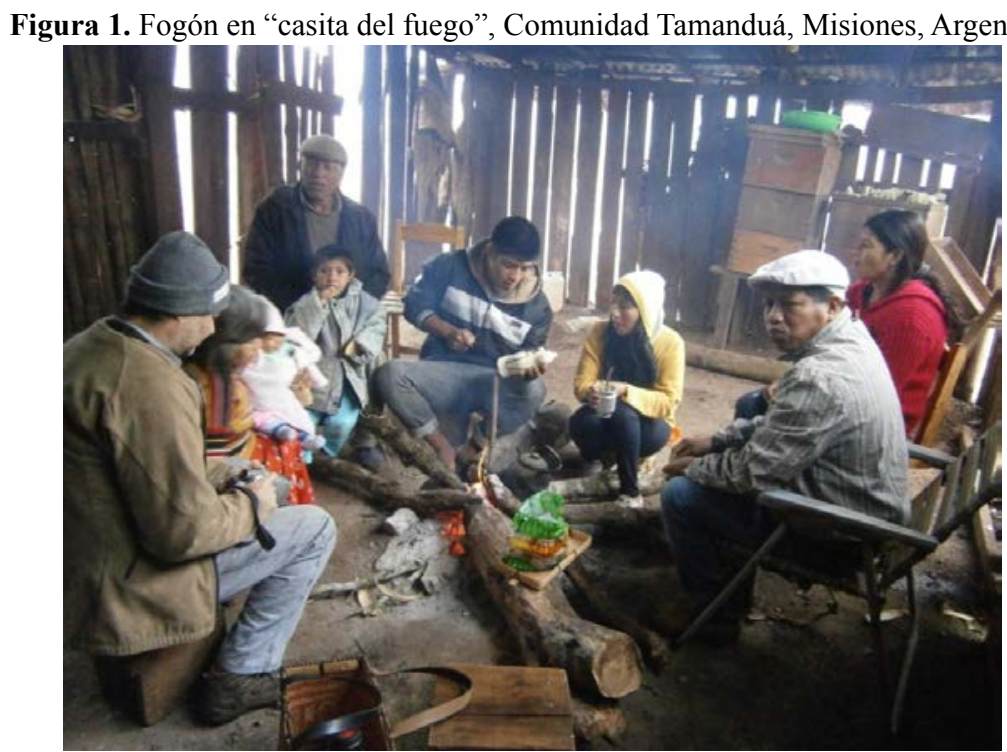

Fuente: Base de datos personal

\section{Tras las huellas}

Para graficar los museos donde se realizaron los relevamientos, presentamos su ubicación geográfica mediante un mapa (Figura 2), que sitúa los sitios exactos de cada una de las instituciones que cuentan con colecciones de Patrimonio Cerámico Guaraní. Se utilizó para ello como Plataforma el Google Earth, que posibilita un viaje o vuelo virtual, que vincula los puntos entre sí, permitiendo además acciones interactivas:

\footnotetext{
Meliá, Bartomeu es doctor en Ciencias Religiosas por la Universidad de Strasbourg. Ha convivido con los Guaraníes de Paraguay, Argentina, Bolivia y Brasil, participando en proyectos, luchas, en especial en relación al territorio y educación indígena no bilingüe. Profesor en la Especialización y Maestría en Culturas Guaraní Jesuítica de la Facultad de Arte y Diseño, Oberá, UNAM.
} 
Figura 2. Mapa con ubicación geográfica de Museos con Patrimonio Cerámico Guaraní

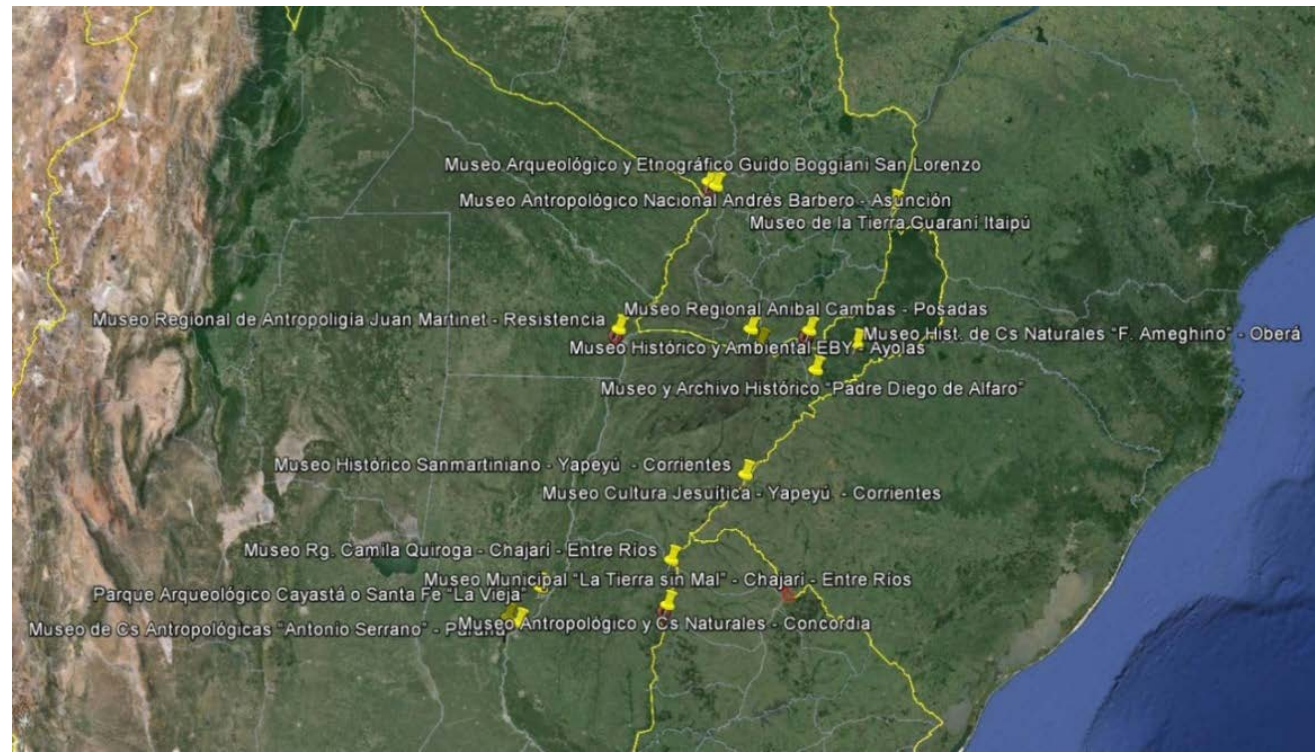

Fuente: Elaboración propia en base a Google Earth

Una de las incursiones más productivas en la ciudad de Posadas, fue en el Museo Histórico y Arqueológico "Andrés Guacurarí, a fin de tomar contacto con su acervo expuesto al público y de acceder al registro fotográfico de colecciones recibidas en donación como las Burna y Nadasdi ${ }^{5}$. Para ello, a partir de la separación de tiestos (Figura 3), se procede a la clasificación de acuerdo a morfología y coloración mediante el encintado de los fragmentos, remontaje de los ceramios (Figura 4), que permite analizar su tipología, tratamiento de superficie, tamaño, usos.

Figura 3. Fragmentos de cerámica guaraní y Figura 4. Remontaje, Museo Andrés Guacurarí, Posadas
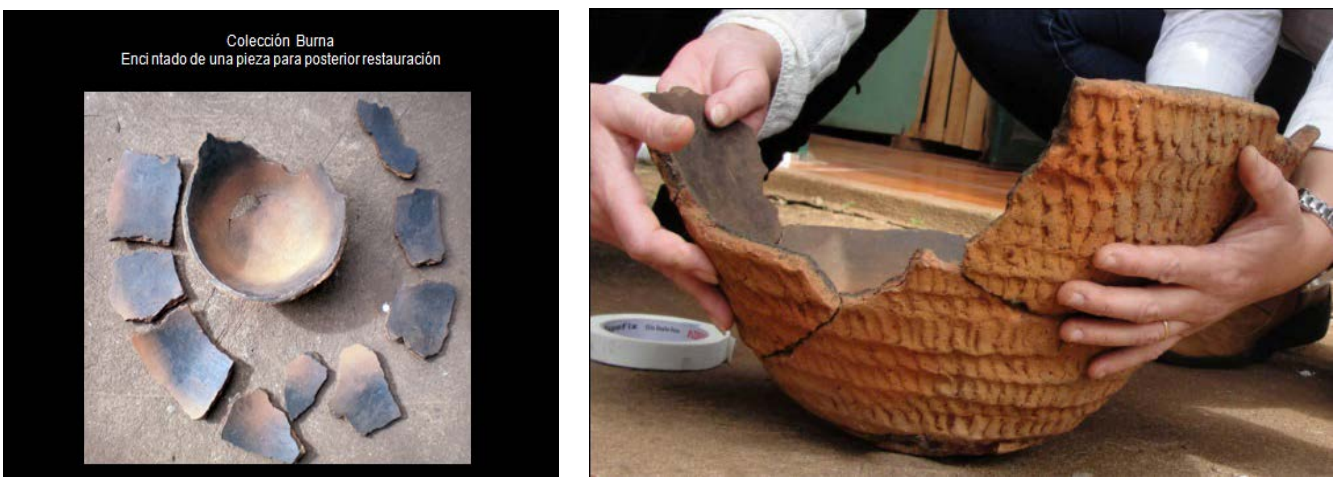

Fuente: Base de datos personal

${ }_{4}$ Museo dirigido por la arqueóloga Ruth Adela Poujade, permitió el registro de los artefactos cerámicos, el día Internacional de los Museos en el año 2010, en ocasión de no estar abierto al público.

5 La colección se hallaba al resguardo en el depósito del museo y su destino se proyecta en el Museo Provincial Miguel Nadasdi, Sarmiento 577, de San Ignacio. 
Otros museos recorridos en la provincia de Misiones, dentro los cuales hemos realizado la recolección de datos e imágenes son: el Regional "Aníbal Cambas" de la ciudad de Posadas; situado en el Parque República del Paraguay, con vistas al río Paraná y el Museo - Archivo Histórico "Padre Diego de Alfaro", conocido como "Casa de Piedra", (Figura 5) por haber sido construido con restos arqueológicos de las Reducciones Jesuíticas, en la ciudad de Apóstoles. Se destaca una urna funeraria con aplicación de engobe blanco en toda la circunferencia del borde, y de engobe rojo en su zona central, careciendo de la zona inferior de forma cónica que era hundida en la tierra, con el objeto de mantener fresca el agua y los alimentos (Figura 6).

Figura 5. Museo Diego de Alfaro, Apóstoles y Figura 6. Vasija arqueológica guaraní
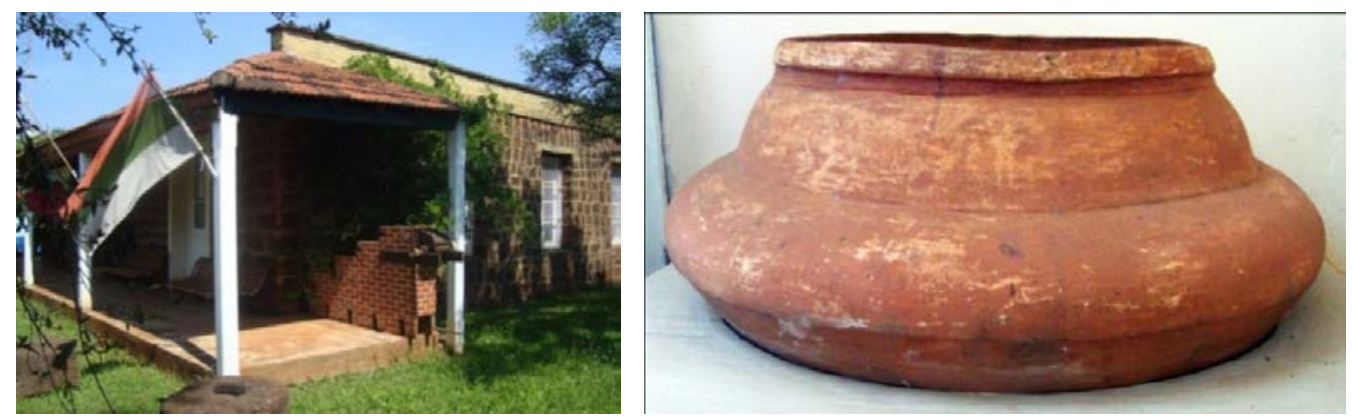

Fuente: Base de datos personal

En la ciudad de Oberá, el Museo Histórico de Ciencias Naturales "Florentino Ameghino" (Figura 7), situado en el Parque de las Naciones, posee una vitrina con objetos arqueológicos y etnográficos de la cultura guaraní.

Es muy particular una pieza mediana de cerámica que ubicada en posición invertida o como se dice comúnmente "boca abajo", presenta un rústico tratamiento de espatulado con importante relieve (Figura 8).

Figura 7. Museo Florentino Ameghino, Oberá y Figura 8. Detalle de corrugado en cerámica guaraní
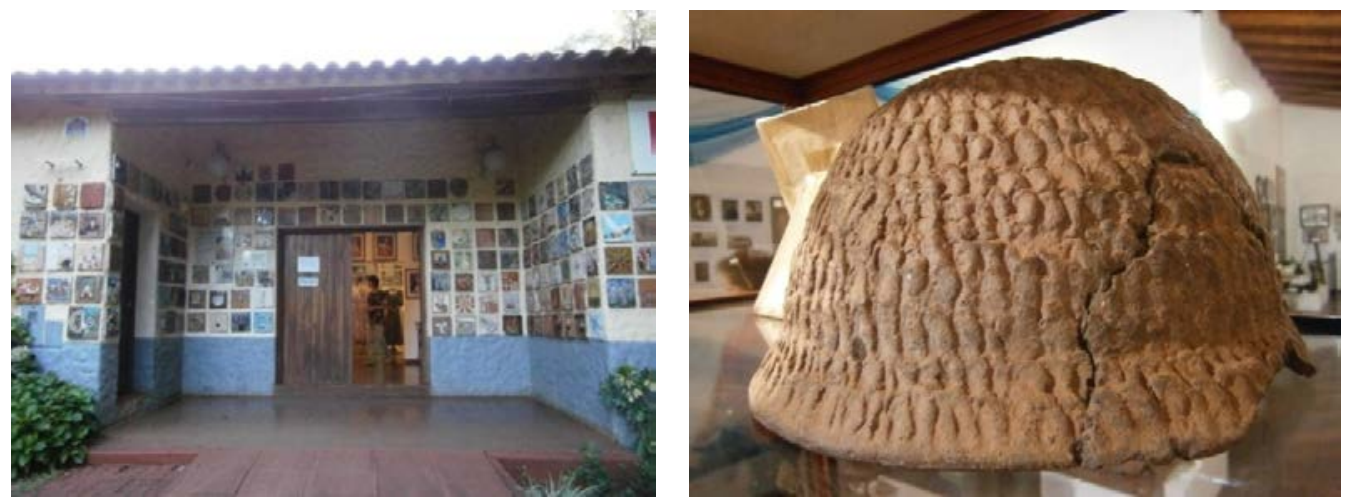

Fuente: Base de datos personal

6 Del Museo Aníbal Cambas contamos con registros realizados desde el año 2006 en adelante, previo a su cierre por remodelaciones en el año 2010; su apertura está prevista antes que finalice el año 2014. 
En el país fronterizo Paraguay, de norte a sur, hemos trabajado en la ciudad de Asunción y alrededores, desde el año 2006 a la fecha, en visitas tanto al Museo Antropológico Nacional Andrés Barbero, donde se conservan las colecciones arqueológicas y etnográficas más importantes del país; como al Museo del Barro, que alberga además el Museo de Arte Indígena (Figuras 9 y 10), y cuenta con trescientas piezas cerámicas precolombinas, de las cuales un centenar corresponde a la cultura guaraní.

Figuras 9 y 10. Colección de Cerámica Arqueológica Guaraní, Museo Del Barro, Asunción, Paraguay
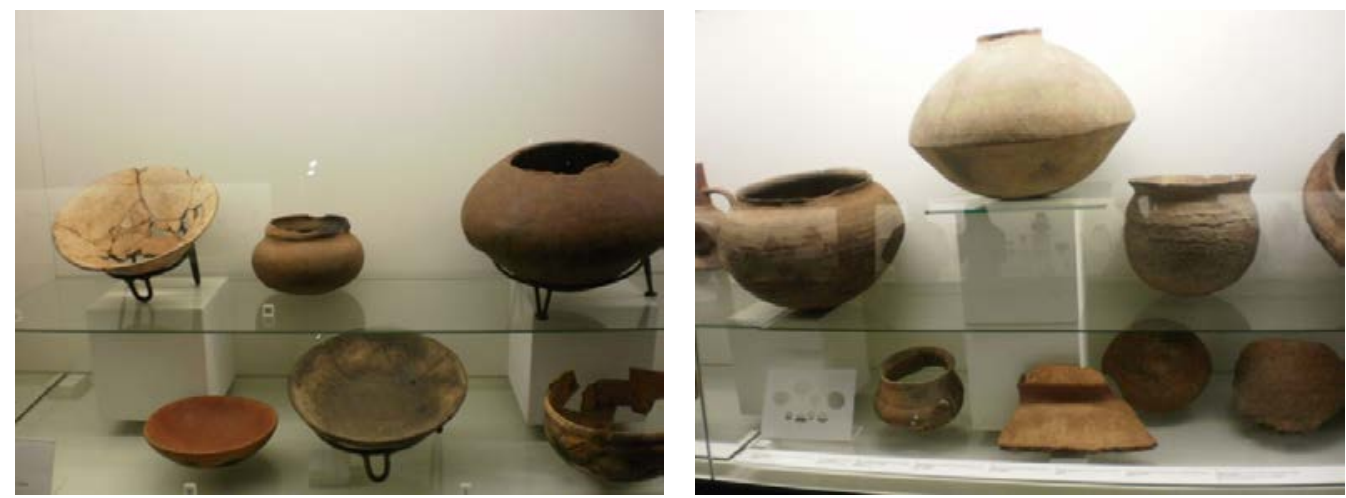

Fuente: Base de datos personal

Otra de las instituciones que preserva los valores de la arqueología paraguaya, con colecciones de indumentaria de diversos pueblos originarios, plumería, cestería, cerámica y objetos de uso cotidiano, de carácter arqueológico y etnográfico de los Guaraní y Zamuko, es el Museo Arqueológico y Etnográfico Guido Boggiani situado en San Lorenzo, Paraguay.

En Ayolas, el Museo Histórico y Ambiental de la EBY ${ }^{7}$, cuenta con numerosas japepó de gran tamaño, cambuchí, ñaetá y ñaembé con aplicación de engobes rojoblanco y otras piezas con variados tratamientos de superficie.

Por último, relevado durante el año 2013, el Museo de la Tierra Guaraní, en Hernandarias, Ciudad del Este, exhibe lo recabado tras la construcción de la represa Itaipú Binacional. (Figuras 11 y 12)

Además de la exposición habilitada al público se brindó la posibilidad de acceder al depósito de bienes en estudio y repositorio, donde observamos primeros planos de las paredes de un ceramio (Figura 13) y vasijas en proceso de restauración (Figura 14).

En tanto en la provincia de Corrientes, nos abocamos a piezas arqueológicas de cerámica guaraní del "Museo Antropológico" y del "Centro de Interpretación de la EBY", ambos ubicados en la ciudad de Ituzaingó. Las mismas también han sido recuperadas luego de excavaciones realizadas al construirse la represa Yacyretá, que

\footnotetext{
7 Entidad Binacional Yacyretá.
} 
dejo inundada la isla Apipé. Se exhiben en vitrinas cuidadas japepó, algunas de las cuales contienen restos de huesos, correspondientes a enterramientos secundarios.

Figuras 11 y 12. Colección de Cerámica Arqueológica Guaraní, Museo de la Tierra Guaraní, Paraguay
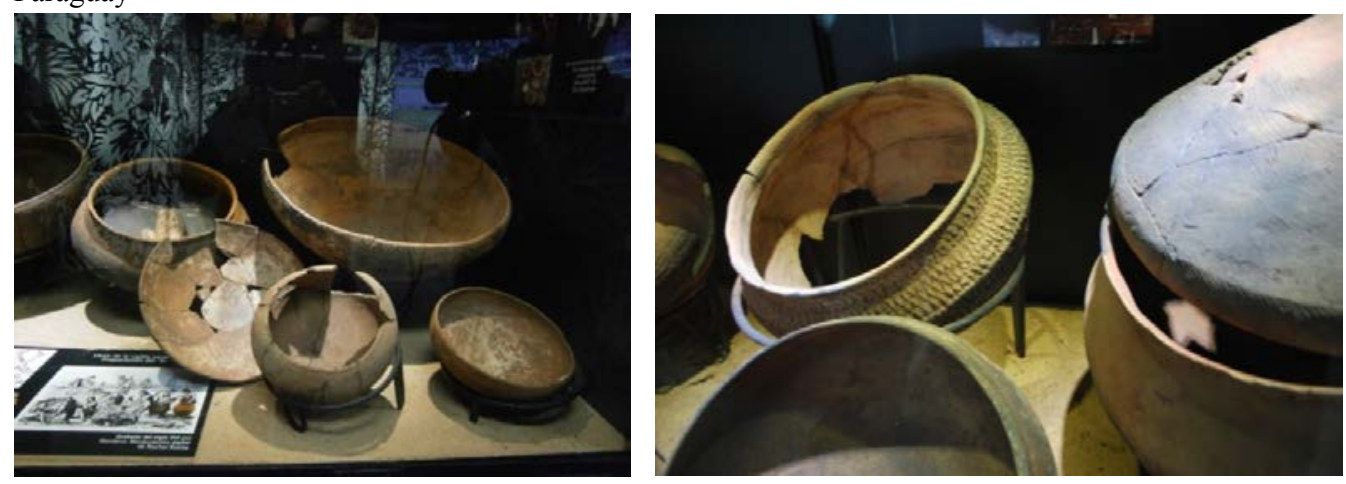

Fuente: Base de datos personal

Figuras 13 y 14. Repositorio Colección de Cerámica Arqueológica Guaraní, Museo de la Tierra Guaraní
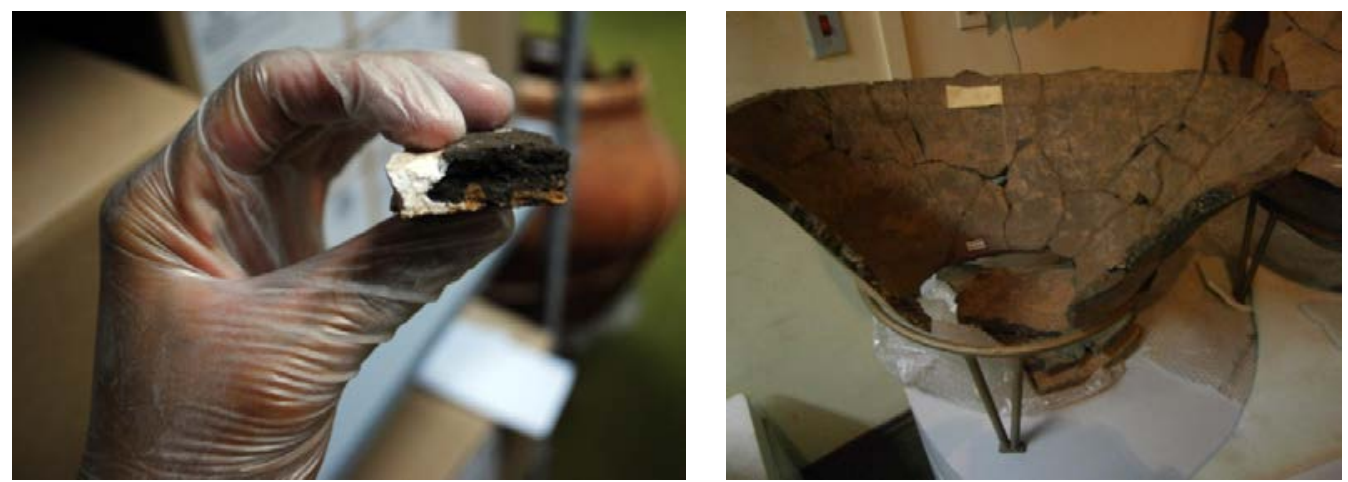

Fuente: Base de datos personal

El "Museo Cultura Jesuítica" y el "Histórico Sanmartiniano", ubicados en Yapeyú, entre sus colecciones cuentan con un reducido patrimonio, consistente en fragmentos de esta cerámica.

En la provincia de Entre Ríos, localidad de Chajarí, se realizaron registros en los Museos “Camila Quiroga” y Municipal Ivy Mara Ey' - "La Tierra sin Mal”, este último, anteriormente radicado en la ciudad del Concepción del Uruguay, posee artefactos etnográficos procedentes de la colección del profesor Juan José Rossi.

En Concordia, el Museo mixto de "Antropología y Ciencias Naturales", dependiente de la Municipalidad cuenta en su patrimonio con vasijas de cerámica guaraní lisas y escobadas, en pequeña escala (Figuras 15 y 16). 
Figuras 15 y 16. Museo de “Antropología y Ciencias Naturales”, Municipalidad de Concordia, Entre Ríos
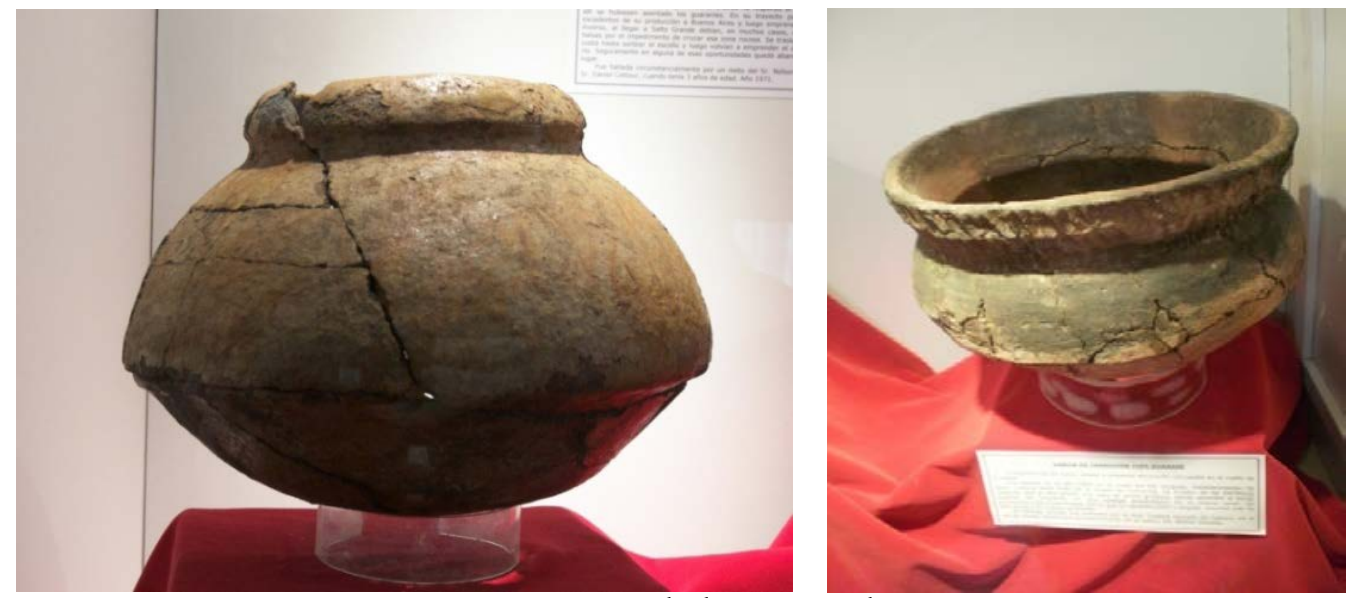

Fuente: Base de datos personal

En la capital de la provincia, Paraná, se ha asistido al Museo de Ciencias Naturales y Antropológicas "Profesor Antonio Serrano", que expone numerosas cerámicas precolombinas, entre las que se destaca una japepó con características particulares en su pintura con engobes. A continuación se puede apreciar un detalle de la urna pintada, que evidencia influencia del contacto con culturas andinas, ingresada al museo en el año 1930, procedente de una de las islas cercanas a Diamante, Entre Ríos. (Figuras 17 y 18)

Figuras 17 y 18. Museo de Ciencias Naturales y Antropológicas “Profesor Antonio Serrano”, Paraná, Entre Ríos
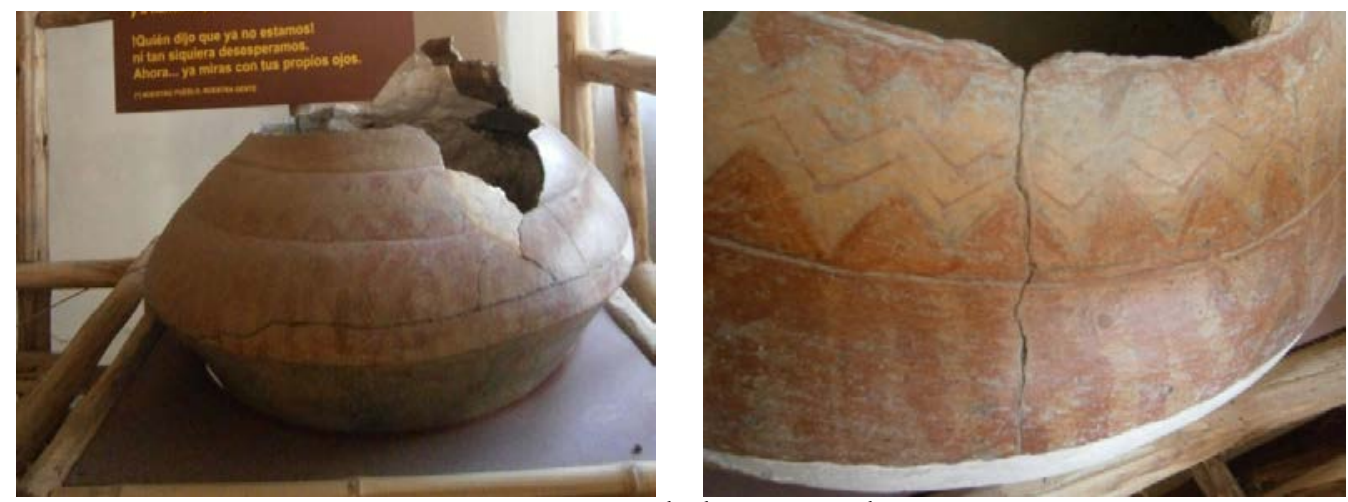

Fuente: Base de datos personal

En dicha Institución la directora del proyecto ha participado del Curso de restauración arqueológica, que permitió la consolidación de fragmentos de una japepó rescatada en la región y de otras piezas precolombinas de culturas del litoral, como así también del resto del país. (Figuras 19 y 20) 
Figuras 19 y 20. Curso de restauración arqueológica y piezas restauradas
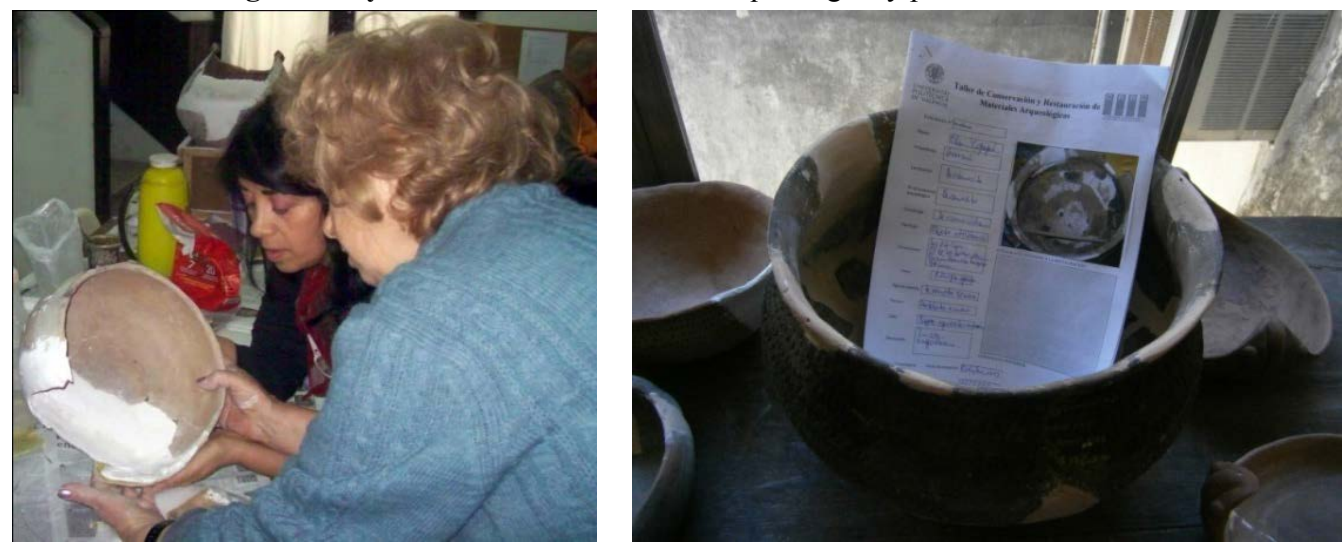

Fuente: Base de datos personal

La experiencia permite al equipo una visión acabada de lo que implica el conjunto de acciones a seguir para el rescate, catalogación, restauración y puesta en valor del patrimonio cerámico guaraní.

También se realizaron visitas al Museo Fundacional del Parque Arqueológico de Cayastá, "La Vieja", de la provincia de Santa Fe, en el año 2012. Allí destacamos un contenedor estilo guaraní de tipo corrugado y un plato con engobe rojo en su fase interna, entre otras piezas de cerámica indígena.

En el Museo Etnográfico y Colonial "Juan de Garay" de la ciudad de Santa Fe, encontramos numerosos objetos cerámicos como un cuenco abierto con pintura roja interna y externa además de tratamiento de texturas entre el cuerpo y el borde exterior.

También podemos mencionar como instituciones dependientes de la Universidad en la Región NEA, el Museo de la Escuela de Antropología Facultad de Humanidades y Artes de la UNR, que cuenta con piezas ubicadas en vitrinas, algunas de las cuales en un estado de conservación no adecuado y el denominado Museo Regional de Antropología "Juan Alfredo Martinet" (Figuras 21-22-23), de la Facultad de Humanidades, UNNE, Resistencia, Chaco, donde hallamos tres platos con aplicación de engobes blanco y rojo en su interior, que denotan su uso ritual y que en las últimas incursiones al museo no vimos expuestos.

Figuras. 21, 22 y 23. Museo Regional de Antropología “Juan Alfredo Martinet”, FH, UNNE, Resistencia, Chaco


Fuente: Base de datos personal 
Para la clasificación de las piezas, Antonio Ruiz de Montoya, Fernando La Salvia y José Brochado, nos aportan elementos distintivos en la construcción de una tipología cerámica. A partir de la interacción entre los equipos interdisciplinarios conformados a lo largo de la investigación, hemos facilitado algunas de las imágenes que integran el exhaustivo trabajo del arqueólogo Mariano Bonomo, proponiendo la catalogación que se observa en la imagen. (Figura 24). En ella observamos las Yapepó o Japepó, olla de cocina (a-b-c-d-e-f-g-h); Cambuchí o recipiente para líquidos (i-j-k-l-m); Naetá, cuenco o cazuela, para uso a fuego directo (n); Naembé, plato profundo para servir y consumir los alimentos (o-p); Cambuchí caguabá o caguavá con forma de vaso o tazón (q-r-s) ; Cambuchí caguabá y Cambuchí juntas (t-u), haciendo la primera las veces de tapa de la olla, a fin de poder aprovechar al máximo el calor del fuego en la cocción de los alimentos.

Vemos que no incluye la Ñamópiu que servía como tostador o asador sobre fuego directo, de acuerdo a la clasificación que hacían Montoya y La Salvia - Brochado. Todas estas piezas se diferencian entre sí a partir de la morfología, el tamaño, el tratamiento de superficie y la función que puede ser utilitaria, de uso cotidiano, o bien como las japepó pasaban a ser de carácter ritual, cuando caían en desuso y se utilizaban como urnas funerarias.

Figura 24. Lámina realizada de manera colaborativa entre equipos interdisciplinarios de la UNLP y la UNaM

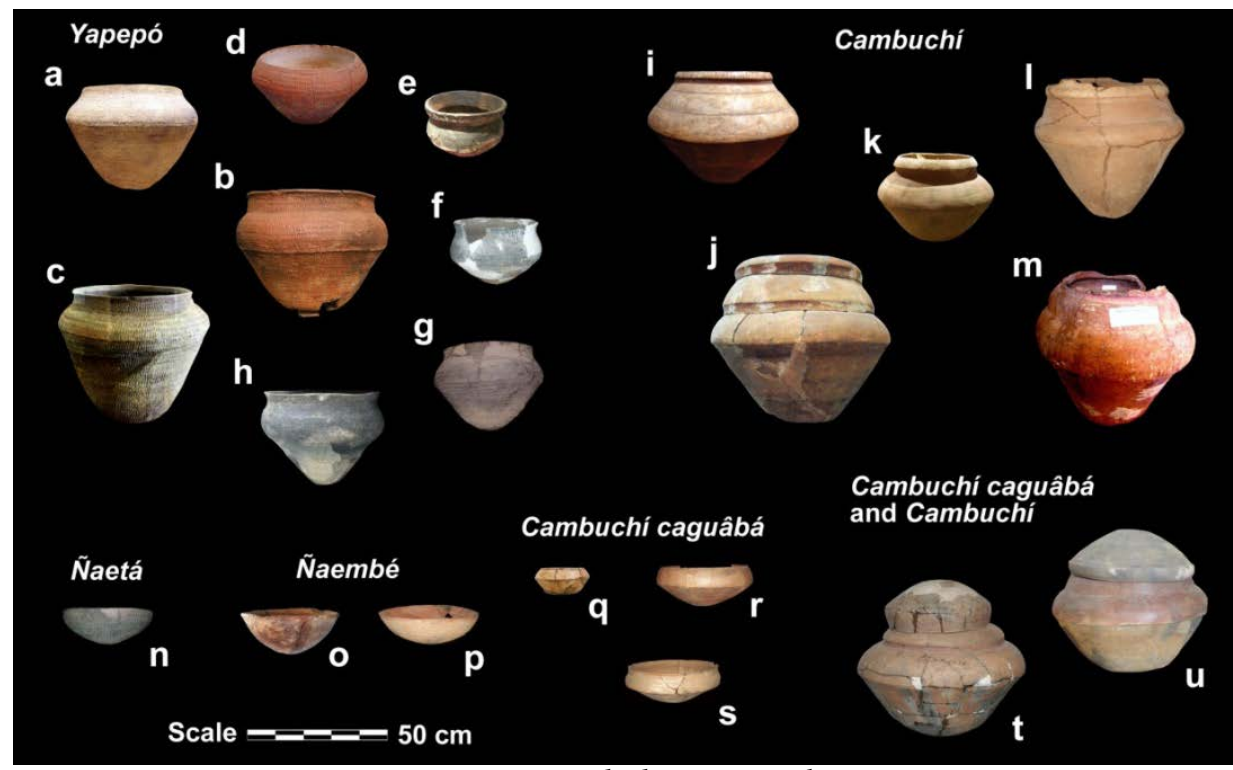

Fuente: Base de datos personal

Por este motivo las japepó, aún hoy son consideradas las más imponentes por su tamaño y complejidad, pues en algunos casos alcanzan grandes dimensiones, lo que evidencia una avanzada tecnología cerámica para su construcción y quema. 
Estos grandes recipientes solían utilizarse como ollas para la preparación de comidas comunitarias, donde según relata el padre Meliá, de su convivencia de aproximadamente diez años junto a ellos, se hervían carnes de animales silvestres, maíz y mandioca, cultivo típico en la zona ${ }^{8}$. Actualmente es común encontrar fragmentos, aunque existen numerosas piezas rescatadas a partir de excavaciones arqueológicas, realizadas con motivo de la construcción de represas y en ese sentido se debe reconocer el buen estado de preservación de las mismas, en espacios de exposición, centros de Interpretación o museos construidos a tal efecto.

Profundizando en detalle el tratamiento de superficie en la fase externa de las cerámicas, presentamos un gráfico con detalles de aplicación de texturas de acabado plástico, diseño y engobes.

Figura.25. Cuadros tratamientos de superficie publicados en el libro "Diálogos"

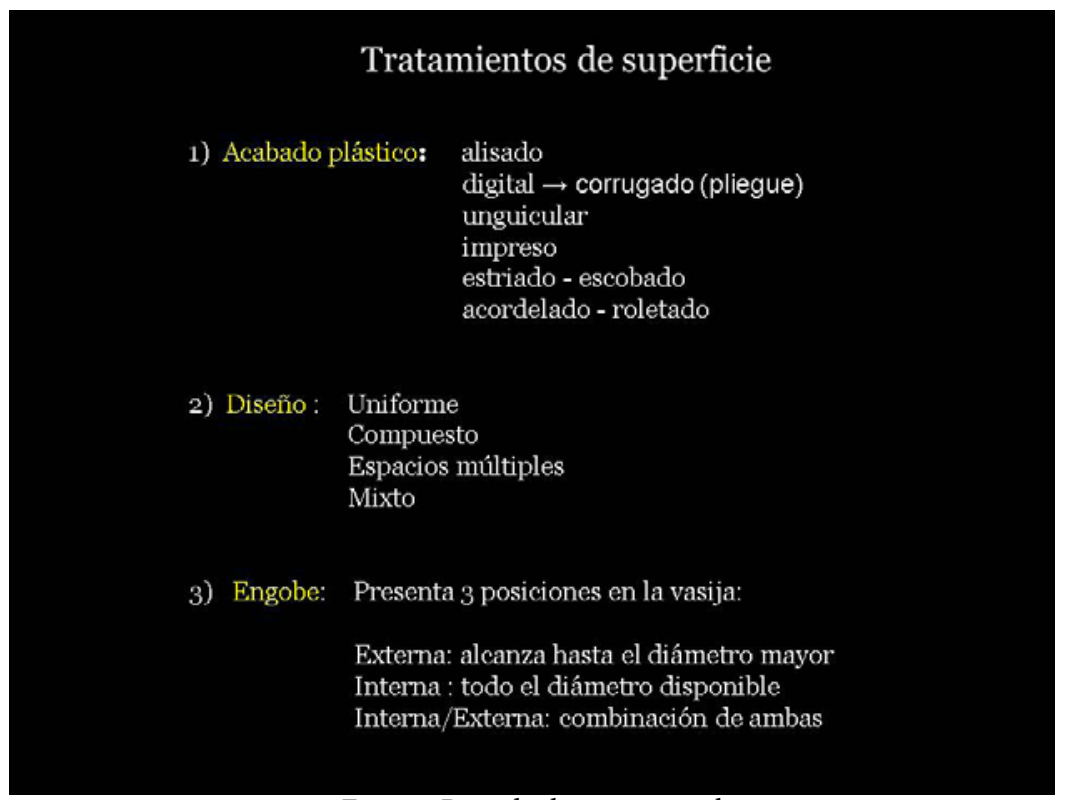

Fuente: Base de datos personal

Por la profusión de fragmentos cerámicos y las características especiales del modelado de las vasijas, mediante el sistema de chorizos o rodetes, es que nos hemos detenido muy especialmente en la diversidad de texturas que distinguen los fragmentos de la región (Figuras 26 y 27).

\footnotetext{
8 Meliá refiere estas anécdotas de su convivencia en distintas aldeas mbyá guaraní de la región, en la Maestría en Culturas Guaraní-Jesuítica, que se desarrolla en la Facultad de Arte y Diseño, Oberá, UNaM. La afirmación se desprende del relato de Mirna Edith Rivas, que asiste a su cursado, y se podría rescatar la desgrabación del registro fílmico (inédito), realizado por Carlos Boián durante el dictado del módulo el día 6 de Junio de 2014. Cabe acotar que Rivas y Boián son integrantes de este equipo de trabajo en investigación.
} 
Figuras 26 y 27. Fragmentos de cerámica arqueológica con variados tratamientos de superficie
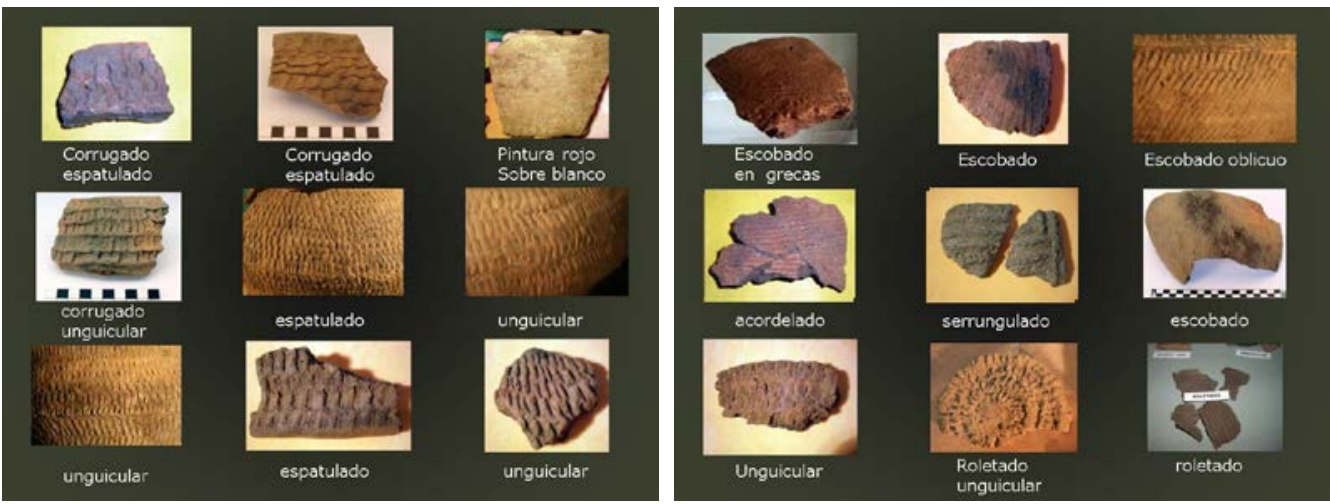

Fuente: Base de datos personal

Al respecto, en Paraguay hemos detectado una importante cantidad de vasijas guaraní pintadas, donde se destacan aquellas que poseen engobes, bruñidos y texturas. En general se observa sobre fondo blanco iconografía en engobe rojo - pintura roja sobre blanca - pintura blanca sobre roja. El rojo, característico de las arcillas locales, (barro ñaú), proviene del óxido de hierro de abundante presencia en toda la región.

El hecho de documentar las colecciones de los mencionados museos, se fundamenta en nuestro interés de presentar publicaciones y material que den cuenta del “...rescate de valores culturales de América; el des-ocultamiento del "encubrimiento" y la preservación y recuperación del patrimonio artístico y cultural que permitan construir otros sentidos de pertenencia”. (Jordán, 2003: 55)

Esta posición y toma de conciencia acerca de los riesgos de perder la posibilidad de incluir estas culturas y su legado, nos permite contemplar "...desde la perspectiva de Paulo Freire, que tanto este rescate de valores como la recuperación del patrimonio cultural, constituyen tareas necesarias para avanzar hacia una educación para la liberación de los pueblos latinoamericanos". A esto, acotaríamos las recomendaciones de Barbosa cuando nos advierte que "...recién en el siglo XX los movimientos de descolonización y de liberación, crearon la posibilidad política para que los pueblos que habían sido dominados reconocieran su propia cultura y sus propios valores" (Barbosa, 2001: 13).

En la Provincia de Misiones, la sociedad en general, los estudiantes y la propia comunidad mbyá, ven restringido su acercamiento al patrimonio cerámico. Los primeros tienen hasta el momento, una visión acotada y a veces, estereotipada del patrimonio cultural guaraní, al que identifican con la cestería y la talla en madera.

En el ámbito educativo, ante hallazgos de restos arqueológicos los maestros afirman que desconocen cómo asesorar, para resguardar este patrimonio. Dan cuenta de esto, expresiones como: -"En mi escuela había un lugar destinado a tiestos cerámicos encontrados en las chacras, por alumnos y sus familiares. Pero, cuando el director se trasladó, el nuevo, hizo limpieza y como justamente estaban refaccionando la escuela, los usaron de escombro".- 
Las inquietudes más recurrentes refieren a la necesidad de reunir herramientas metodológicas, respecto a cómo proceder para preservar un espacio donde se detecta un fragmento. Por otra parte, se hace evidente que los habitantes, descendientes de los Mbyá Guaraní, conocen a partir de las tradiciones orales el hecho de que sus antepasados realizaban producciones cerámicas, pero en general, no cuentan con objetos cerámicos

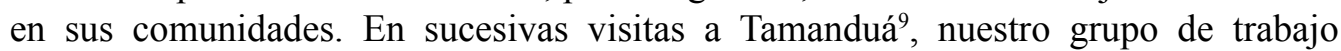
comprueba que las imágenes correspondientes a piezas arqueológicas existentes en los museos, coinciden con los relatos obtenidos desde la memoria de sus mayores (Figura 28) que tampoco han sabido de ellas en los distintos niveles de formación a los que han podido acceder.

Figura 28. Presentación multimedial del libro digital "Diálogos", en comunidad Tamanduá, Misiones.

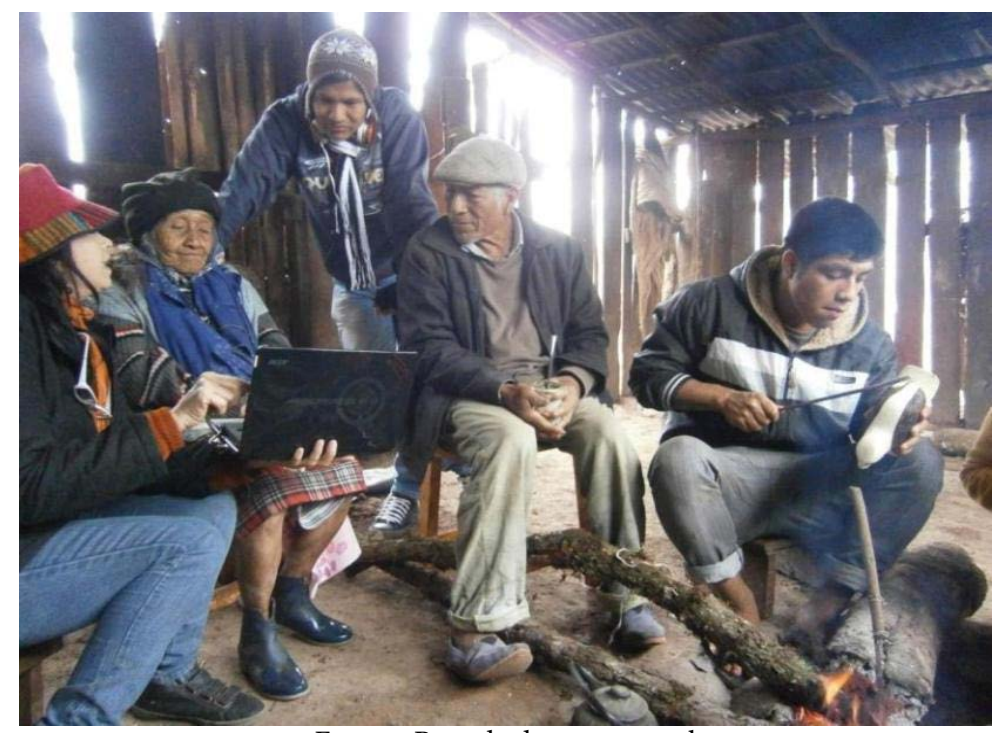

Fuente: Base de datos personal

De acuerdo a lo manifestado por caciques y miembros del consejo de ancianos de las comunidades, además de conocer la cerámica de sus antepasados, su interés es rescatar la práctica alfarera guaraní. En la actualidad, el único tipo de objeto cerámico modelado y cochurado en fogones es la pipa ceremonial o petynguá (Figura 29), que solo puede ser usada por los sabios ancianos junto al opyguá o líder espiritual. Esta se realiza en pequeñas cantidades, en algunas aldeas donde poseen yacimientos de "barro ñaú" o "arcilla". Dado que la mujer ha sido desde los tiempos ancestrales del que hacer cerámico, es que se designa a una de ellas la confección de las mismas y la distribución a las aldeas que las requieran.

9 Tamanduá, Comunidad Mbyá Guaraní cercana a la ciudad de 25 de Mayo, Provincia de Misiones. 
Figura 29. Pipa ceremonial o "petynguá" de terracota con anillo de semillas

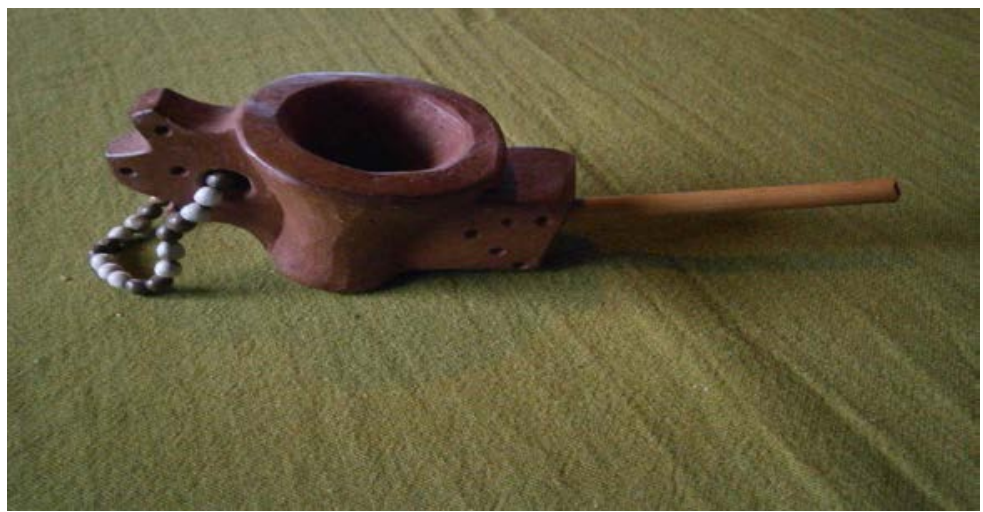

Fuente: Base de datos personal

\section{Hallazgos - consideraciones}

A partir de lo expuesto hasta el momento, en vistas a contribuir al fortalecimiento e identificación de un territorio multicultural, consideramos oportuna la realización de una ajaká o cesta (Figuras 30 y 31), confeccionada por la comunidad mbyá, que además de contener las piezas que recrean los modos de producción cerámica, incorpora un DVD editado que refiera a los nombres de estos objetos en idioma guaraní con su respectiva tipología y una guía orientadora de pasos a seguir ante posibles hallazgos de tiestos arqueológicos. Estimamos que este dispositivo favorecería a la comprensión del público en general y de los originarios en particular y propiciaría de parte de estos últimos, la identificación del objeto arqueológico de sus ancestros.

Para finalizar, consideramos que esta propuesta puede coadyuvar al conocimiento de la cerámica guaraní, fortalecer la historia local, y contribuir a la puesta en valor del patrimonio desde los actores involucrados.

Figuras 30 y 31. Ajaká y piezas de recreación cerámica de tipología arqueológica guaraní
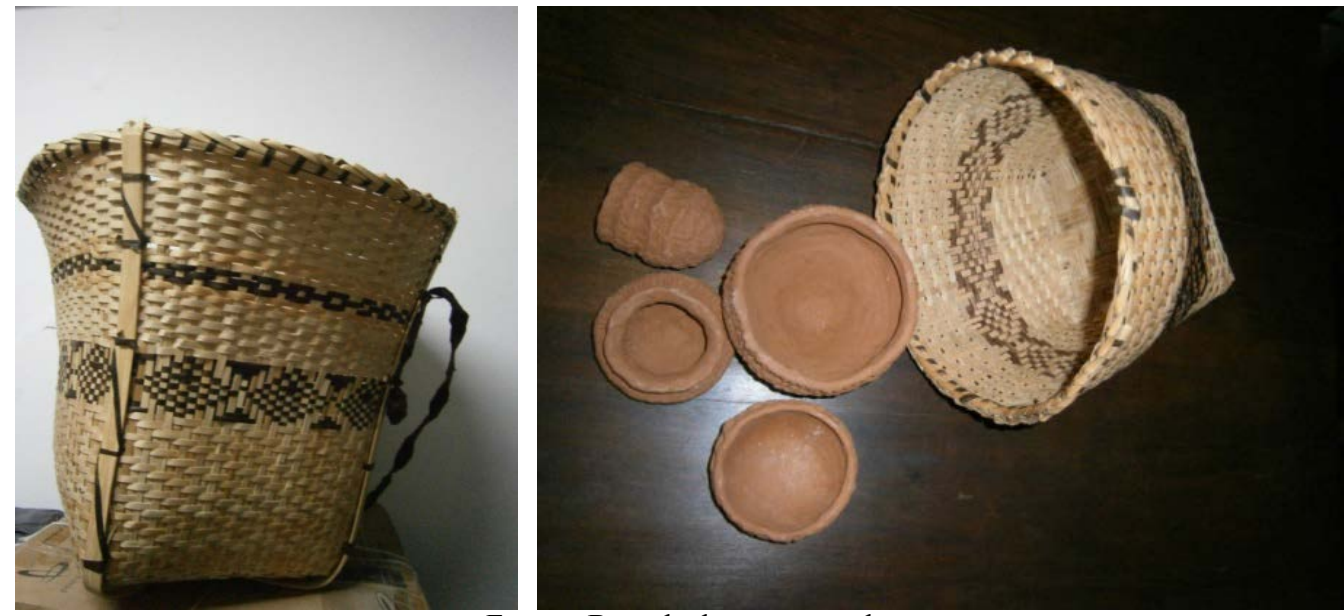

Fuente: Base de datos personal 


\section{Referencias bibliográficas}

Barbosa, A. 2001. A Imagen no Ensino da Arte, Sao Pablo, Editora Perspectiva.

Bogado, B. 2010. La tierra y el ser. Poesías de un Mbyá Guaraní, Encarnación, Aldea Pindó.

Bonomo, M. 2012. Historia prehispánica de Entre Ríos, Buenos Aires, Fundación de Historia Natural Félix de Azara.

Bonomo, M.; Angrizani R. C; Apolinaire E. y Silva Noelli F. 2014. "A Model for the Guaraní Expansion in the La Plata Basin and in the Littoral of Southern Brazil". En prensa en Quaternay International, [En línea] URL: http:/www.journals. elsevier.com/quaternary-international/

Capucci, V. Z. 1987. Fragmentos de cerâmica brasileira, Brasilia, Brasiliana.

Catálogo Museo Regional “Aníbal Cambas”. 2006. Posadas.

Censo Indígena Nacional. 1986. Ministério del Interior. Tomo 2. Buenos Aires.

Cerâmica de Apiaí. Museo de Arte de São Pablo (catálogo). Du Pont. Marprint São Pablo.

Escobar, T. 1993. La belleza de los otros: Arte Indígena del Paraguay, Asunción, RP ediciones.

Galeano Olivera, David A. 2002. Antropología Avakuaaty, Asunción, Serie Ateneo de Lengua y Cultura Guaraní.

Jordán, S.; Dormond, A. y otros. 2013. Cerámica guaraní de pueblos originarios del Nordeste Argentino, Norte de Paraguay y Sur de Brasil, Editorial Universitaria. Posadas, Misiones.

Jordán, S. y equipo. 2011. Diálogos. Intercambio cultural entre producciones de comunidades de pueblos originarios y artistas - artesanos contemporáneos. Posadas.

Jordán, S. 2003. ¿Qué es escultura? Las Representaciones sobre Escultura de los alumnos de artes. Posadas, Tesis de Maestría en Docencia Universitaria en Biblioteca Regional Oberá. UNaM.

La Salvia F. y Brochado J.1989. Cerâmica guarani, Porto Alegre, Posenato Arte \& Cultura.

Maeder, Ernesto y Gutiérrez Ramón. 1994. Atlas Histórico y Urbano del Nordeste Argentino. Pueblos de indios y misiones jesuiticas, Resistencia, CONICET / FUNDANOR.

Melià, B. (1997). El guaraní conquistado y reducido, ensayos de etnohistoria, Asunción Biblioteca Paraguaya de Antropología.

Melià, B. 2008.Educación indígena y alfabetización, Asunción, Centro de Estudios Paraguayos "Antonio Guasch".

Revista Nordeste, Historia No 26. 2007. Serie: Investigación y Ensayos, Resistencia, UNNE.

Revista Nordeste, Historia No 29. 2009. Serie: Investigación y Ensayos, Resistencia, UNNE.

Oliveira, M. 2004. História e arte guarani: Interculturalidade e identidade. Santa María, UFSM. 
Pla, J. 2006. La Cerámica Popular Paraguaya, Asunción, CDI del Centro de Artes Visuales / Museo del Barro.

Rossi, J. J. 2005. Diseños nativos de la argentina: clásicos y actuales, Buenos Aires, Galerna - Búsqueda de Ayllu.

Sánchez, M. y González N. 2002. El cruce: Cuestiones sobre arte contemporáneo del Paraguay. "Identidades en tránsito”, Asunción, Centro de Artes Visuales/Museo del Barro.

Santinelli, C. 2006. A Cerâmica Guarani e Guarani Missioneira. Curso de Restauração da cerâmica sul-americana. Série Cooperação N. 29. Roma, Instituto Italo-Latino Americano.

Serrano, A. 1966. Manual de la Cerámica Indígena, Córdoba, Assandri,

Sondereguer, C. y Marziali, M. 2001. Cerámica Precolombina. Catalogo de morfologia, Buenos Aires, Corregidor.

Sondereguer, C. 2010. Diseño precolombino. Catálogo de iconografía. MesoaméricaCentroamérica - Suramérica, Buenos Aires, Corregidor.

Sondereguer, C.; Punta, C. 2005. Amerindia. Introducción a la etnohistoria y las artes visuales precolombinas, Buenos Aires, Corregidor.

Susnik, B. 1998. Artesanía Indígena: Ensayo Analítico, Asunción, El lector,

Vidal, L. 2007. Grafismo Indígena. Sao Paolo, Studio Nobel.

\section{Recursos electrónicos}

Lima Rocha, R. (2009). [En línea] Consultado 9 de abril, URL:www.ugr. es/ arqueologyterritorio/PDF6/Lima.pdf

[En línea] Consultado 15 de mayo, URL:http://www.itaipu.gov.br/es/turismo/museode-la-tierra-guarani

[En línea] Consultado 20 de mayo, URL: http://www.irfabolivia.org/?p=928

[En línea] Consultado 25 de mayo, URL:http://www.itaipu.gov.br/es/turismo/museode-la-tierra-guarani

[En línea] Consultado, 2 de junio, URL: http://www.ellitoral.com.ar/es/articulo/253039/ Yapeyu-proponen-crear-una-comision-protectora-del-patrimonio-arqueologico

[En línea] Consultado 5 de junio, URL:http://www.guiaturista.com.ar/destino/chajari/ excursion/museo-municipal-ivy-mara-ey---la-tierra-sin-mal.html

[En línea]Consultado 6 de junio, URL: http://www.unatierradiferente.com/historia-ycultura/museo-de-antropologia-y-ciencias-naturales-de-concordia.htm

[En línea] Consultado 7 de junio, URL: http://museocienciasnaturalesuader.blogspot. com.ar/2007/11/museo-provincial-de-ciencias-naturales.html

Instituto Nacional de Asuntos Indígenas (INAI). Información estadística. Información extraída de la encuesta complementaria de pueblos indígenas. Ministerio de Desarrollo Social, Presidencia de la Nación, [En línea] Consultado 8 de junio, URL: http://www.desarrollosocial.gob.ar/Uploads/i1/Institucional/6. InformacionEstadistica.pdf 